\title{
Performance of Bioplant for Municipal Solid Waste at Jatinangor Campus of Institut Teknologi Bandung
}

\author{
Mochammad Chaerul \\ Department of Environmental Engineering, Faculty of Civil and Environmental Engineering, Institut Tekologi Bandung, Ganesha 10 \\ Bandung 40132 INDONESIA
}

\begin{abstract}
Although Law No. 18 year of 2018 has mandated recycling to be prioritized in solid waste management, the municipality intend to collect and to dump the waste directly to landfill. By cooperating with National Gas Company (PT. PGN), bioplant was constructed at area of $200 \mathrm{~m}^{2}$ and operated at Jatinangor Campus of Institut Teknologi Bandung to treat organic waste generated from the campus and traditional market near the campus. The study aims to evaluate the performance of the bioplant in term of biogas generation and composition during the pilot project. Main treatment at the bioplant is anaerobic digestion $(\mathrm{AD})$ using two units with single-stage and wet fermentation. Organic waste as feeding had $62 \%$, $61 \%$ of water and volatile contents, respectively. Carbon organic and total Nitrogen contributed $8.19 \%$ and $0.22 \%$, respectively. $200 \mathrm{~kg}$ of the organic waste daily was mixed with ratio of $1: 1$ with water. Total volume biogas generated daily from 2 units of $\mathrm{AD}$ was $2.1 \mathrm{~m}^{3}$ with composition of $45 \%, 15 \%$, and $10 \% \mathrm{of}_{4}$, $\mathrm{CO}_{2}$ and $\mathrm{O}_{2}$, respectively. Due to the waste reduction at source, various potential negative impacts due to open dumping commonly operated at landfill site in Indonesia could be avoided.
\end{abstract}

\section{Introduction}

Municipal Solid Waste (MSW) management is considered a serious environmental challenge confronting local authority. Environmentally sound Municipal Solid Waste Management (MSWM) now become a global challenge due to increasing population and urbanization, especially in developing countries [1]. Currently, several countries have realized that the way they manage their solid wastes does not satisfy the objectives of sustainable development throughout the world $[2,3]$.

According to Law No. 18 year of 2018 on Waste Management, MSWM in Indonesia should adopt a new paradigm by putting 3R (Reduce Reuse Recycle) concept implementation as the first priority; rather than just collecting, transporting and subsequently disposing the waste in final disposal site. The Law also requires each residential and commercial areas to provide the waste segregation facility, so that it is expected that the $3 \mathrm{R}$ activities can take place more efficiently [6].

Waste recycling can be done through the process of composting for organic waste generated from household and other domestic sources. While aerobic composting requires oxygen supply for the process, decomposition of organic waste in the absence of oxygen (anaerobic digestion) generates biogas in closed-reactor namely anaerobic digester / $\mathrm{AD} /$ biodigester. Biogas has high heating value as it mainly consists of methane gas which is economically valuable to use for several purposes.
During the digestion process, it generates also other by product in the form of liquid and solid composts which is useful as soil conditioner. Thus, anaerobic digestion offers more benefits compared to the aerobic composting $[4,5]$.

As it is demanding by the National Policy direction to generate and to utilize more a New and Renewable Energy, National Gas Company (Perusahaan Gas Negara / PT. $P G N$ ) has formulated the strategic policy to develop alternative energy sources from biomass (including organic waste). In order to implement the policy, PT. PGN has requested to Institut Teknologi Bandung (ITB) to build and operate $\mathrm{AD}$ with other supporting facility (so it calls as bioplant) at Jatinangor campus. The study aims to evaluate the performance of the bioplant in term of biogas generation and composition during the pilot project.

\section{Methodology}

\subsection{Design of bioplant}

The bioplant at Campus of Jatinangor ITB was built as implementation of cooperation between PT. PGN and ITB. In general, the bioplant which occupied $200 \mathrm{~m} 2$ area consists of several facilities namely:

1. Feeding preparation area; Organic waste transported and unloaded to the bioplant came from internal and external sources (canteen, student dormitory, office

Corresponding author: m.chaerul@ftsl.itb.ac.id 
etc and traditional market). $200 \mathrm{~kg}$ daily of organic waste was shredded and mixed with water with ratio 1:1 of weight. The mixture was then stored in a drum for 5 days to as representation of hydrolysis stage.

2. Anaerobic digester / AD (biodigester); two units of ferrocement-cube with diameter of $2.5 \mathrm{~m}$ and $2.3 \mathrm{~m}$ depth was built as main treatment unit. At the beginning, $\mathrm{AD}$ was filled with the mixture of manure and rumen as starter until half capacity of AD. The starter was allowed to stay in $\mathrm{AD}$ for 2 weeks before $\mathrm{AD}$ was ready to receive the feed. The hydraulic retention time (HRT) for process in $\mathrm{AD}$ was expected to be 10 days, before the residue of liquid and slurry were overflowed automatically and collected in the storage unit. Biogas produced from the fixed-dome $\mathrm{AD}$ was streamed using $3 / 4$ inch of PVC pipe to biogas storage unit.

3. Biogas handling unit; Valve to stream the biogas from the $\mathrm{AD}$ to the storage was starting to open since the digestate overflowed. Biogas storage unit in the form of cube with diameter of $2.5 \mathrm{~m}$ and $2.0 \mathrm{~m}$ height was built using ferrocement with light weight of plastic as cover. The unit was filled up with water so that biogas that is generated could lift up the cover. Scale was installed in the unit to measure the height of cover raised so that the volume of biogas generated daily can be determined. Biogas was then streamed using $3 / 4$ inch of plastic hose to biogas purification to get more methane gas. Biogas purification used a drum consist of $\mathrm{Ca}(\mathrm{OH})_{2}$, iron shaving and activated carbon to remove the impurities such as $\mathrm{CO}_{2}$ and $\mathrm{H}_{2} \mathrm{~S}$ in the stream. Similar with biogas storage unit, purified-biogas storage has diameter of $2.0 \mathrm{~m}$ and $1.5 \mathrm{~m}$ height.

4. Supporting facility; In addition, the bioplant was supported with several facilities such as stove for biogas utilization, workshop, reservoir for water supply, waste shredder machine, office space, toilet and gardening area for utilization of liquid and slurry by-product.

\subsection{Analysis of feeding}

The quantity of organic waste to be shredded and its physical composition was daily measured in wet-weight basis. Water and volatile contents, and ratio of Carbon and Nitrogen was analyzed in Laboratory of Solid and Hazardous Waste, Faculty of Civil and Environmental Engineering, ITB. The output of the hydrolysis stage was also analyzed in the same laboratory for parameter of $\mathrm{C} / \mathrm{N}$ ratio.

\subsection{Biogas measurement}

Biogas generated from bioplant was measured daily after the by-product was overflowed to the storage unit. The volume of gas generation was determined by comparing the height of cover raised for each consecutive day and volume of biogas utilized at a respective day. The composition of biogas and purified-biogas was measured using mobile gas analyzer.

\section{Results and discussion}

\subsection{Characteristic of feeding}

The quantity of organic waste received from the sources varied during the pilot project. Ideally, the water added for the waste shredding process is same with the quantity of organic waste shredded. Practically, quantity of water required was depend on the composition of organic waste shredded into slurry. In average, during the pilot project $201 \mathrm{~kg}$ per day of organic waste mixed with 200 liters of water (Figure 1).

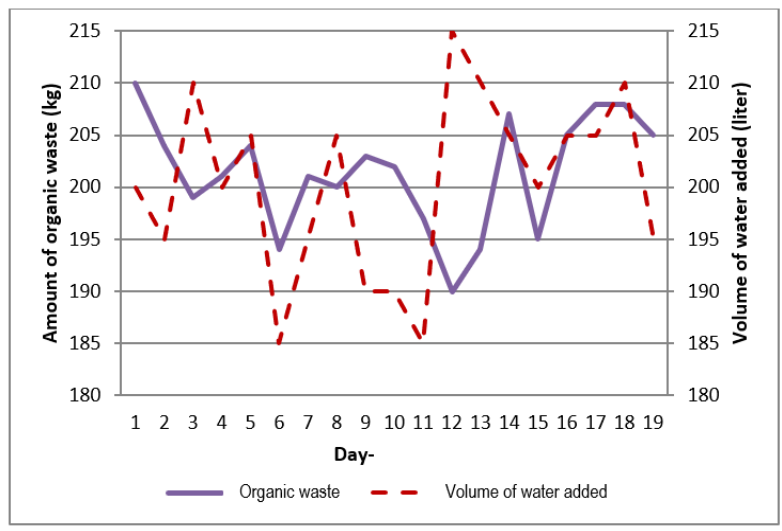

Fig. 1. Quantity of organic waste and water added.

Organic waste unloaded and shredded at the bioplant was dominated by vegetables which have high fiber contain. Time required to decompose them was longer than other organic waste type like food and fruit wastes. The average of waste organic composition can be found in Figure 2 below. In average, vegetables, fruit and food wastes contributed $37 \%, 32 \%$, and $31 \%$, respectively for total organic waste to be shredded.

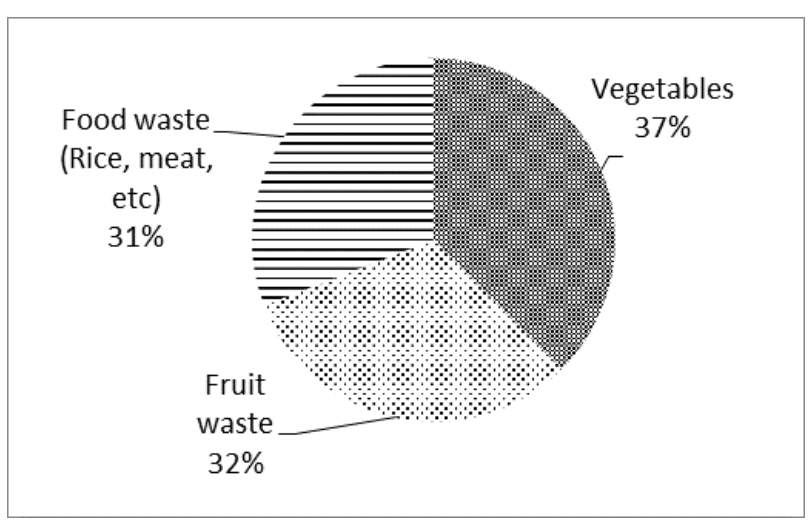

Fig. 2. Composition of organic waste.

Water and volatile contents, and ratio of Carbon and Nitrogen for the feed to be shredded can be seen in Table 1 below. Water content was so high as the experiment was conducted at the beginning of rainy season in Indonesia. While, the difference of organic waste composition did not result to the fluctuated of volatile content measured. In average, the water and 
volatile contents of the organic waste to be shredded was $62 \%$ and $61 \%$, respectively.

By considering water and volatile contents, it could be calculated that the organic loading as feeding was 3.3 $\mathrm{kg} / \mathrm{m} 3 /$ day of volatile solid. The loading was categorized as high rate digester [8]. By adopting high rate digester, the parameter process such as temperature, $\mathrm{pH}$, and mixing should be more monitored intensively. However, in this study, such of monitoring was not conducted and it might affect the biogas generation.

Table 1. Characteristic of feeding (organic waste).

\begin{tabular}{|c|c|c|}
\hline $\begin{array}{c}\text { Day- of } \\
\text { measurement }\end{array}$ & $\begin{array}{c}\text { Water } \\
\text { content (\%) }\end{array}$ & $\begin{array}{c}\text { Volatile } \\
\text { content (\%) }\end{array}$ \\
\hline 1 & 57 & 61 \\
\hline 4 & 55 & 63 \\
\hline 7 & 59 & 60 \\
\hline 10 & 61 & 60 \\
\hline 13 & 68 & 62 \\
\hline 16 & 68 & 61 \\
\hline 19 & 69 & 60 \\
\hline Average & 62 & 61 \\
\hline
\end{tabular}

To represent hydrolysis stage at the beginning, the organic waste was processed in separate drums. From the analysis, it was found the 5-days process was able to reduces the ratio of $\mathrm{C} / \mathrm{N}$ (Table 2). Though it was not so high, the hydrolysis stage was expected to break the long chain of carbon in the organic waste into shorter one, so as it would be easier to decompose in biodigester. From the hydrolysis stage, the average ratio of $\mathrm{C} / \mathrm{N}$ was reduced from 37,24 to 34,76 .

Table 2. Ratio of $\mathrm{C} / \mathrm{N}$ before and after hydrolysis process.

\begin{tabular}{|c|c|c|c|c|c|c|}
\hline \multirow{2}{*}{$\begin{array}{c}\text { Day- of } \\
\text { feeding }\end{array}$} & \multicolumn{2}{|c|}{ Before hydrolysis } & \multicolumn{3}{c|}{ After Hydrolysis } \\
\cline { 2 - 7 } & $\begin{array}{c}\mathbf{C} \\
(\%)\end{array}$ & $\begin{array}{c}\mathbf{N} \\
(\%)\end{array}$ & $\begin{array}{c}\text { Ratio } \\
\mathbf{C} / \mathbf{N}\end{array}$ & $\begin{array}{c}\mathbf{C} \\
(\%)\end{array}$ & $\begin{array}{c}\mathbf{N} \\
(\%)\end{array}$ & $\begin{array}{c}\text { Ratio } \\
\mathbf{C} / \mathbf{N}\end{array}$ \\
\hline 1 & 8.2 & 0.23 & 35.65 & 8.0 & 0.24 & 33.33 \\
\hline 7 & 8.0 & 0.22 & 36.36 & 7.8 & 0.22 & 35.45 \\
\hline 13 & 8.5 & 0.23 & 36.96 & 8.4 & 0.25 & 33.60 \\
\hline 19 & 8.0 & 0.20 & 40.00 & 7.7 & 0.21 & 36.67 \\
\hline Average & $\mathbf{8 . 2}$ & $\mathbf{0 . 2 2}$ & $\mathbf{3 7 . 2 4}$ & $\mathbf{8 . 0}$ & $\mathbf{0 . 2 3}$ & $\mathbf{3 4 . 7 6}$ \\
\hline
\end{tabular}

\subsection{Characteristic of digestate}

Solid residue or digestate is rich in nutrients and organic matter produced by anaerobic digestion that has a promising potential to be used as soil amendment [7].

The characteristic of digestate produced in the study can be found in Table 3 below. The digestate was overflowed from $\mathrm{AD}$ to digestate storage since day \#7. It means that the actual HRT was only 7 days. The characteristic of digestate was analyzed for every week during the pilot project.

Table 3. Characteristic of solid digestate.

\begin{tabular}{|c|c|c|c|c|c|}
\hline $\begin{array}{c}\text { Day- of } \\
\text { measurement }\end{array}$ & $\begin{array}{c}\text { Water } \\
\text { content } \\
(\%)\end{array}$ & $\begin{array}{c}\text { Volatile } \\
\text { content } \\
(\%)\end{array}$ & $\begin{array}{c}\mathbf{C} \\
(\%)\end{array}$ & $\begin{array}{c}\mathbf{N} \\
(\%)\end{array}$ & $\begin{array}{c}\text { Ratio } \\
\mathbf{C} / \mathbf{N}\end{array}$ \\
\hline 7 & 89.2 & 53.5 & 7.1 & 0.21 & 33.81 \\
\hline 13 & 85.9 & 55.1 & 7.5 & 0.22 & 34.09 \\
\hline 19 & 92.2 & 56.9 & 6.3 & 0.25 & 25.20 \\
\hline Average & $\mathbf{8 9 . 1}$ & $\mathbf{5 5 . 2}$ & $\mathbf{7 . 0}$ & $\mathbf{0 . 2 3}$ & $\mathbf{3 1 . 0 3}$ \\
\hline
\end{tabular}

Compared with those finding in feeding and after hydrolysis, the ratio of $\mathrm{C} / \mathrm{N}$ in digestate was decrease. Concentration of organic matter was still high proving that it required more times to decompose further. Hence, in order to use it as compost, the digestate needs further post-treatment.

Comparing the data available in Table 2 and 3, it could be resumed that organic and volatile removal produced by the AD are $9.6 \%$ and $15.0 \%$. The efficiency removal would affect the biogas generation and composition.

\subsection{Biogas generation and composition}

Biogas generation produced from $\mathrm{AD}$ can be seen at Figure 3 below. Biogas generated from anaerobic digestion was affected by amount of volatile matter decomposed.

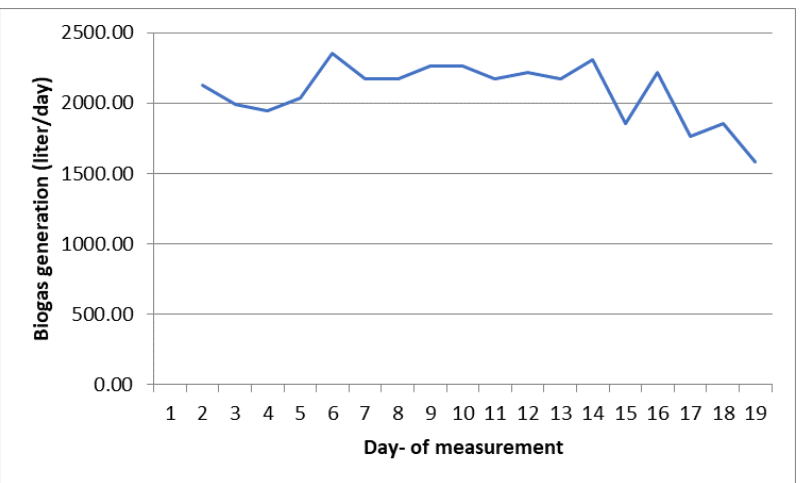

Fig. 3. Biogas generation.

At the beginning, the biogas generation was high as the $\mathrm{AD}$ dominantly decomposed the manure as the starter. After digestate was starting to overflow in day\#7, 
the generation of biogas was relatively constant until day\#14. It was predicted that manure as starter was washed out along with the digestate overflowed. After day\#14, the generation of biogas was vary affecting mostly by the characteristic of the feeding. The trends of biogas generation seemed to be decrease. The process in $\mathrm{AD}$ might need longer duration to be adapted completely with all organic waste as feeding.

By considering amount of organic waste as feeding to $\mathrm{AD}$ and volume gas produced, the yield of biogas from this study became $10.0 \mathrm{~L} / \mathrm{kg}$ of organic waste or equals to $175 \mathrm{~L} / \mathrm{kg} \mathrm{VS}$. The yield was quite low compared to other study $[9,10]$. In order to get higher yield, it might need to decrease organic loading and prolonged the HRT.

Though it was dominantly produced in the study, the proportion of methane was lower than $50 \%$. The system was not so isolated as the oxygen was still found in the stream. The composition of biogas can be seen in Figure 4 below. By this proportion, the biogas might only be used for cooking purpose.

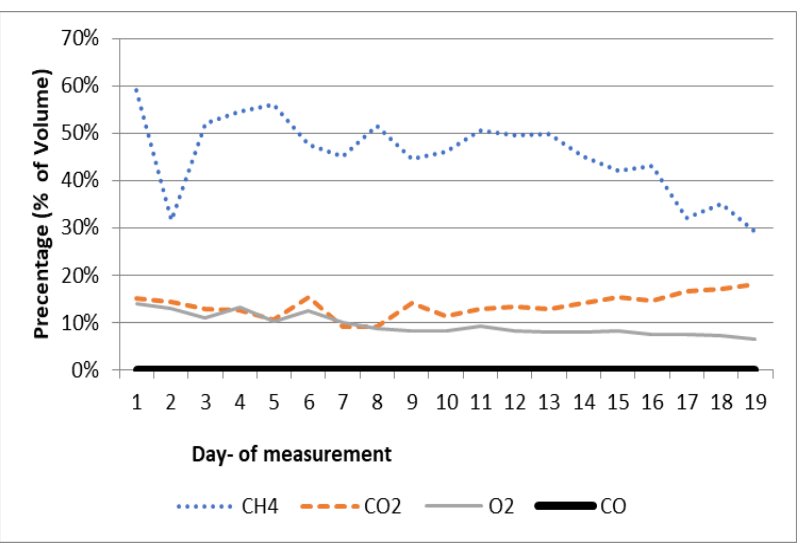

Fig. 4. Composition of biogas.

In the study, application of a simple biogas purification unit was proved to increase the proportion of methane to $40-60 \%$. More proportion of methane was needed when the biogas would be applied for electricity generation. The efficiency of biogas purification could be found in Figure 5 below.

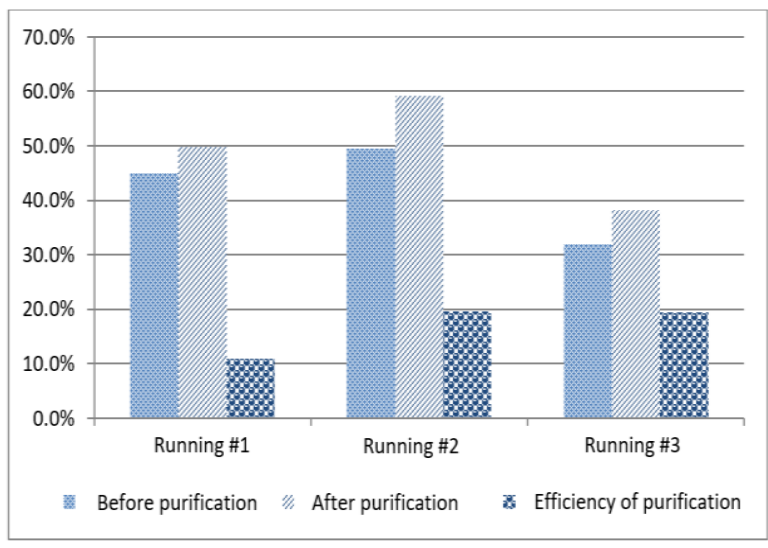

Fig. 4. Performance of biogas purification

\section{Conclussion}

Anaerobic digestion was adopted to treat $200 \mathrm{~kg}$ daily of organic waste generated in Jatinangor campus of ITB and a traditional market near the campus. With the cooperation with National Gas Company (PT. PGN), several facilities such as feeding preparation area, $\mathrm{AD}$ as a main unit, biogas handling unit and other supporting facilities have been designed and built in the bioplant site.

$\mathrm{AD}$ adopted fixed-dome unit and wet fermentation process to decompose organic waste. The yield of biogas produced was quite low (2.0 m3 daily) as the organic loading was so high and hydraulic retention time was so short. By applying simple biogas purification unit, the proportion of methane could achieve $40-60 \%$.

Though the performance quite low, the existence of bioplant becomes important as part of municipal solid waste management especially for Indonesia to reduce the quantity of waste to be transported to final disposal. Biogas and digestate were also useful for daily activity of waste generator. Bioplant might become example of best practice of generating energy from waste within premises. In addition, the bioplant could be utilized as field of laboratory for academic purpose in ITB.

\section{References}

1. T.V. Ramachandra, H.A. Bharath, G. Kulkarni, S.S. Han. Renew. and Sust. Ener. Rev. 82 (2018)

2. S. Seo, T. Aramaki, Y. Hwang, K. Hanaki. J. of Env. Eng. 130, 1 (2004)

3. N.P. Thanh, Y. Matsui, T. Fujiwara. Env. Monit. Assess. 175, 1 (2011)

4. J. Perez, J.M. Andres, J. Lumbreras, E. Rodríguez. J. of Clean. Prod. 205 (2018)

5. M.S. Korai, R.B. Mahar, M.A. Uqaili. 2017. Renew. and Sust. Ener. Rev. 72 (2017)

6. H. Sudibyo, Y.S. Pradana, A. Budiman, W. Budhijanto. Ener. Proc. 143 (2017)

7. C. Knoop, C. Dornack, R. Raab. Waste Man. 72 (2018)

8. W.A.K. Ghani, A. Idris. 2009. J. of Eng. Sci. and Tech. 4, 4 (2009)

9. Y. Vogeli, C.R. Lohri, A. Gallardo, S. Diener, C. Zurbrugg. Anaerobic Digestion of Biowaste in Developing Countries: Practical Information and Case Studies. (Swiss Federal Institute of Aquatic Science and Technology (Eawag), Dübendorf, Switzerland, 2014)

10. R. Kigozi, A. Aboyadeand, E. Muzenda. 2014. Intl. J. of Res. in Chem., Metall. and Civ. Eng. 1, 1 (2014) 